\title{
A METHOD FOR EVALUATING THE MAXIMUM TSUNAMI LOADINGS ON SEAWALLS
}

\author{
Takuya Toriyama, Kisaburo Azuma, Hiroshi Moritani, and Nobuo Ishida ${ }^{1}$
}

\begin{abstract}
A seawall in a nuclear power station is one of the important structures to protect from tsunami. Estimation of tsunami loadings on structures is an important part of the proper design of seawalls. In this study, hydraulic flume tests was conducted to investigate the characteristics of tsunami loadings. Correlations between the loading on a seawall and the Froude number as characteristics of the tsunami flow were investigated. Finally, we proposed a new evaluation method to evaluate the design wave pressure on a seawall. A new evaluation method can predict the design wave pressure on a seawall with taking the characteristics of the tsunami flow into consideration.
\end{abstract}

Keywords: seawall, wave pressure test, wave pressure evaluation, design method

\section{INTRODUCTION}

A seawall in a nuclear power station is one of the important structures to protect facilities from tsunami inundation and tsunami damage. Therefore, it is important to understand the characteristics of the tsunami wave pressure acting on the seawall in order to ensure a seawall protection function against the tsunami. Moreover, it is important to develop the appropriate design wave pressure evaluation method taking the characteristics of the tsunami wave pressure into consideration.

The tsunami wave pressure acting on a seawall changes with time, as shown in Fig. 1. The Bore wave pressure, which impacts at the leading-edge of tsunami, changes largely in a short time. The continuous wave pressure, which exerts after the bore wave pressure, acts on a seawall for a relatively long time. However, "Effects of Bore Pressure of Tsunami on Seawalls" (NTEC-2015-4001, Nuclear Regulation Authority (hereinafter, referred to as the "NRA")) confirmed that the structural influence of bore wave pressure on a seawall generally becomes smaller than that of the continuous wave pressure. Therefore, this paper focused on the effect of the continuous wave pressure by summarizing "Water Depth Coefficients for Evaluating Tsunami Pressure on Seawall" (NTEC-2016-4001, NRA).

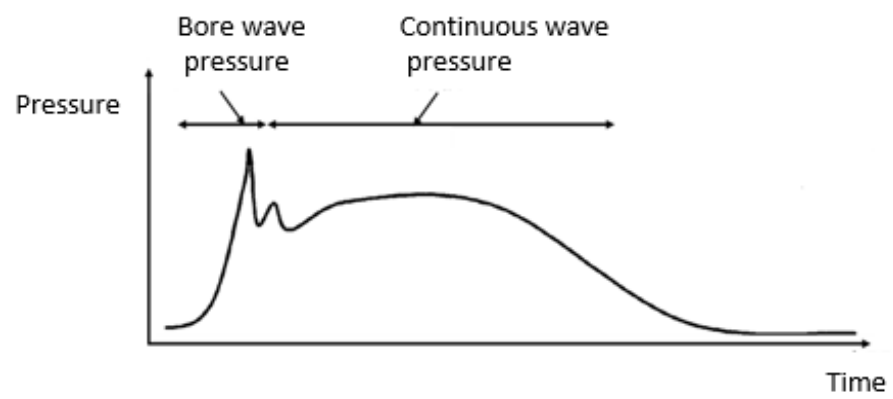

Figure 1. Wave pressure acting on a seawall.

In Japan, the method mentioned in "The interim guidelines of the Ministry of Land, Infrastructure, Transport and Tourism" (hereinafter, referred to as the "MLIT method") is generally used as the design wave pressure evaluation method. The MLIT method is the method to evaluate the design wave pressure acting on the seawall as shown in Fig. 2. The design wave pressure is obtained from the hydrostatic pressure equivalent to the height of three times the design run-up water depth. In this method, the design run-up water depth is the inundation water depth where the seawall stand. The time when the run-up water depth becomes the maximum is commonly used as the representative time, and the run-up water depth at the representative time is used as the design run-up water depth.

\footnotetext{
${ }^{1}$ All the authors belong to, Division of Research for Earthquake and Tsunami, Regulatory Standard and Research Department, Secretariat of Nuclear Regulation Authority (S/NRA/R), 1-9-9 Roppongi-First Building, Roppongi, Minato-ku, Tokyo, 106-8450, Japan
} 


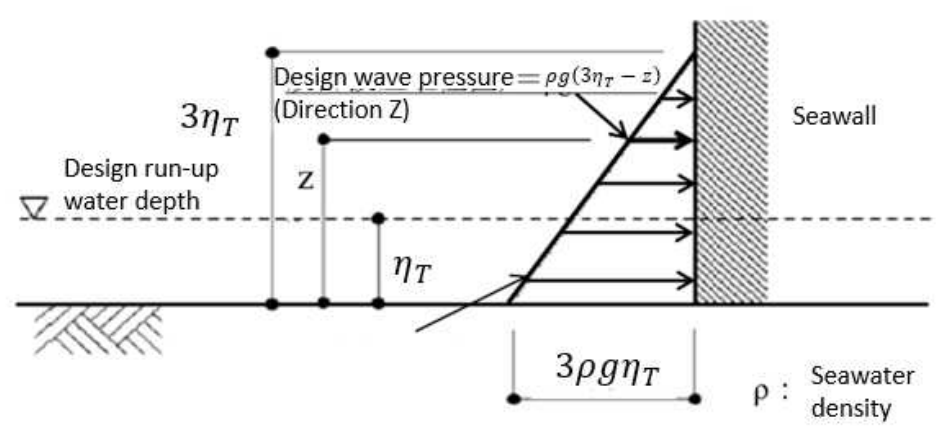

Figure 2. Design evaluation methods of tsunami wave pressure by MLIT method.

Because the height of three times the design run-up water depth is the value obtained in limited experimental cases, the applicable condition of the MLIT method should be confirmed, and a new design evaluation method should be developed in case of exceeding the applicable limitation.

This paper confirmed the applicable condition of the MLIT method which was used as the design wave pressure evaluation method acting on the seawall. We conducted some hydraulic flume tests and developed a new design evaluation method in case of exceeding the applicable limitation.

\section{HYDRAULIC FLUME TESTS}

\section{Run-up test}

Two kinds of hydraulic flume tests were carried out: the run-up test and the wave pressure test.

First of all, the run-up test was carried out to evaluate the flow characteristics without the seawall model. Parameters of the flow characteristics are the Froude number $(F r(t))$ and the specific energy $(E(t))$. The Froude number $(F r(t))$ is a non-dimensional number indicating the ratio of the fluid inertial force to gravity. The Froude number $(F r(t))$ is obtained from the run-up water depth $(\eta(t))$ and the flow velocity $(v(t))$ as shown in Eq. 1 . Where, $\mathrm{g}$ is a gravitational acceleration.

$$
\operatorname{Fr}(t)=v(t) / \sqrt{g \eta(t)}
$$

Since the tsunami is a non-steady flow, we need to select the representative location and time. The representative location is the point where the seawall model stands. As for the representative time, the time when the run-up water depth becomes the maximum during the continuous wave region (hereinafter, referred to as the "the maximum continuous run-up water depth $\left(\eta_{\max \_2 n d}\right)$ ") is commonly used. In this paper, the continuous wave region is defined as the time span after the maximum water depth in front of the seawall (Fig. 3). The Froude number $\left(F r_{\eta}\right)$ is obtained from the maximum continuous run-up water depth $\left(\eta_{\text {max } 2 n d}\right)$ and the flow velocity at the representative time.

The specific energy $(E(t))$ is the total water energy per unit weight (total hydraulic head). It is based on the Bernoulli's theorem of non-viscous, steady, and one-dimensional flow as shown in Eq. 2.

$$
E(t)=0.5 v(t)^{2} / g+\eta(t)
$$

\section{Wave pressure test}

Secondly, the wave pressure test was carried out to evaluate the characteristics of the continuous wave pressure $\left(P_{2 n d}(t)\right)$, which acted on the seawall model in the continuous wave region. The water depth coefficient $\left(\alpha_{T}\right)$ is a non-dimensional number relating to the maximum continuous wave pressure $\left(P_{\max \_2 n d}\right)$ acting on the seawall model. The water depth coefficient $\left(\alpha_{T}\right)$ represents the ratio of the maximum continuous wave pressure $\left(P_{\text {max } 2 n d}\right)$ to the hydrostatic pressure, which is equivalent to the design run-up water depth $\left(\eta_{T}\right)$, as shown in Eq. 3.

$$
\alpha_{T}=\frac{P_{\max 2.2 n d}}{\rho g \eta_{T}}
$$

Where, $\rho$ is the water density. The maximum continuous run-up water depth $\left(\eta_{\text {max_2nd }}\right)$ obtained from the run-up test is commonly used as the design run-up water depth $\left(\eta_{T}\right)$ to evaluate the water depth 
coefficient $\left(\alpha_{T}\right)$. The water depth coefficient using the maximum continuous run-up water depth $\left(\eta_{\text {max }} 2\right.$ 2nd $)$ is defined as the water depth coefficient $\left(\alpha_{\eta}\right)$.

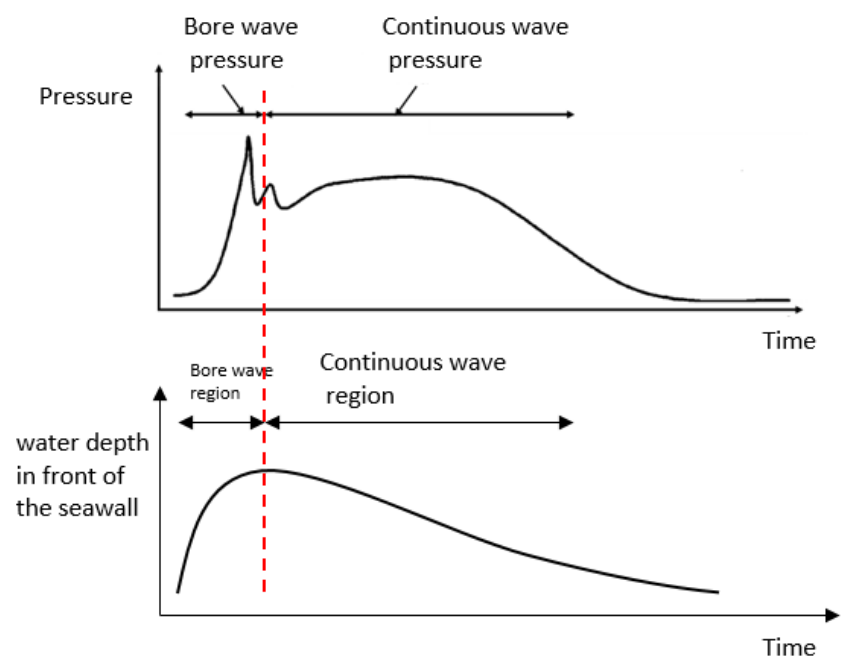

Figure 3. Demarcation of continuous wave pressure and bore wave pressure.

\section{Schematics of hydraulic flume}

The schematics of the hydraulic flume are shown in Fig. 4. The figure shows locations of the seawall model, the wave height gauges and the velocity gauges. The hydraulic flume was $47 \mathrm{~m}$ in length and $0.8 \mathrm{~m}$ in width. The seawall model was $0.8 \mathrm{~m}$ in height and $0.79 \mathrm{~m}$ in width, $0.01 \mathrm{~m}$ in thickness made of aluminum assuming the scale of $1 / 40$. The wave pressure gauges were set on the seawall model surface (Fig. 5).

The locations of the seawall model were at the shoreline, $1.25 \mathrm{~m}$ and $2.5 \mathrm{~m}$ distant from the shoreline, assuming the distances of $0 \mathrm{~m}, 50 \mathrm{~m}$ or $100 \mathrm{~m}$ from the shoreline to the seawall. The bed slopes near the shoreline were 0 and $1 / 20$. The generated waveforms were solitary waves $\left(\mathrm{W}_{01}, \mathrm{~W}_{02}\right)$, sine waves $\left(\mathrm{W}_{03}\right.$ to $\left.\mathrm{W}_{08}\right)$, and long period waves $\left(\mathrm{W}_{09}\right.$ to $\left.\mathrm{W}_{12}\right)$ (Fig. 6). The solitary wave $\left(\mathrm{W}_{01}\right)$ and the long period wave $\left(\mathrm{W}_{09}\right)$ break in front of the seawall model. 

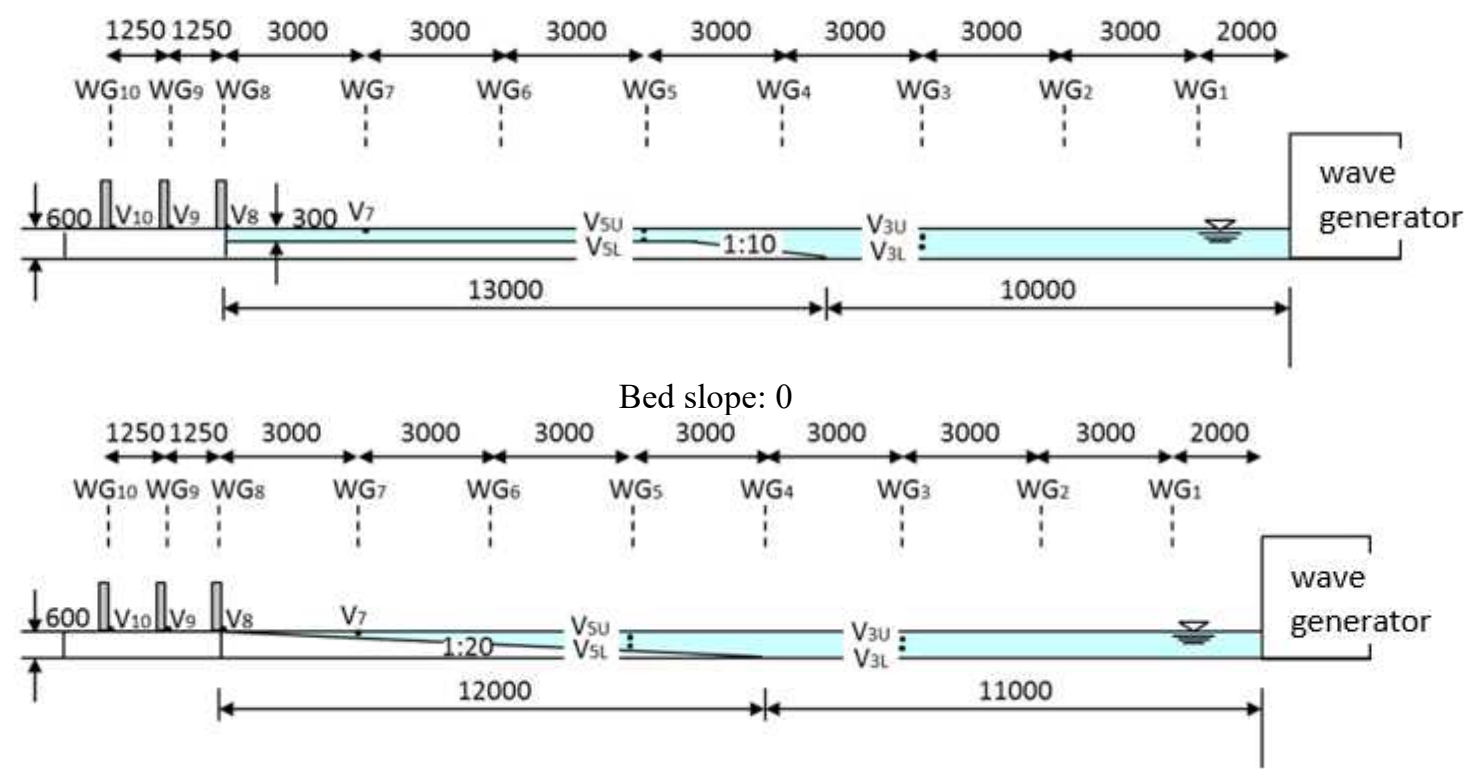

Bed slope: $1 / 20$

* $\mathrm{WG}_{\mathrm{i}}(\mathrm{i}=1-10)$ is the wave height gauges, $\mathrm{V}_{3 \mathrm{U}}, \mathrm{V}_{3 \mathrm{~L}}, \mathrm{~V}_{5 \mathrm{U}}, \mathrm{V}_{5 \mathrm{~L}}, \mathrm{~V}_{7}$ are electromagnetic velocity gauges, $\mathrm{V}_{8}$ is propeller-type velocity gauges, and $\mathrm{V}_{9}, \mathrm{~V}_{10}$ are bottom-surface electromagnetic velocity gauges.

Figure 4. Schematics of hydraulic flume.

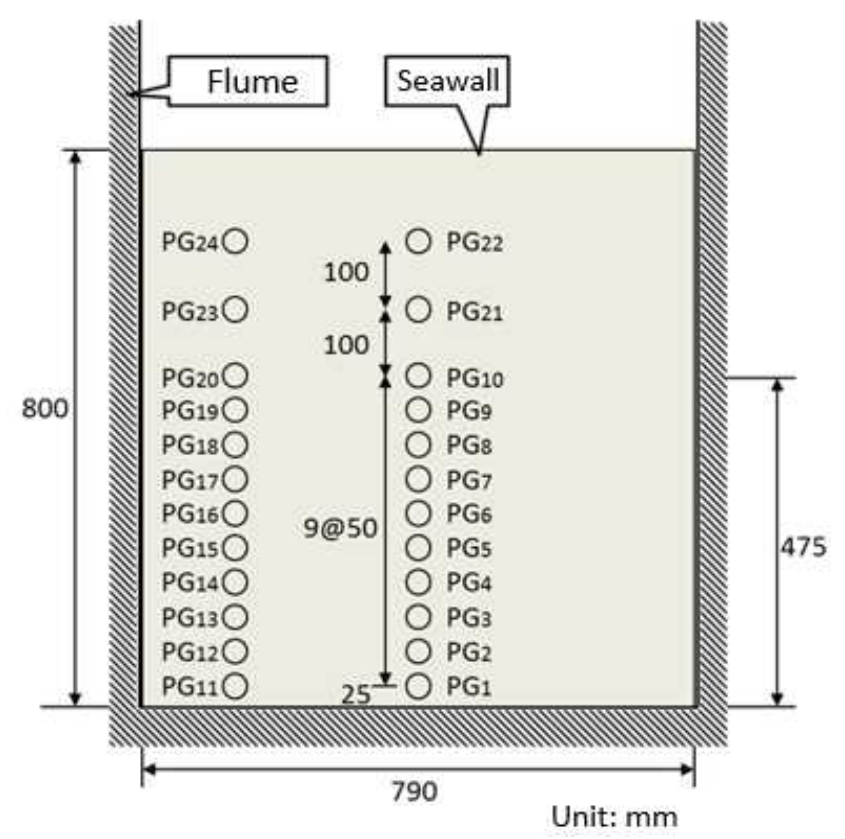

* $\mathrm{PG}_{\mathrm{n}}(\mathrm{n}=1-24)$ is wave pressure gauges

Figure 5. Positions of gauges on seawall model. 

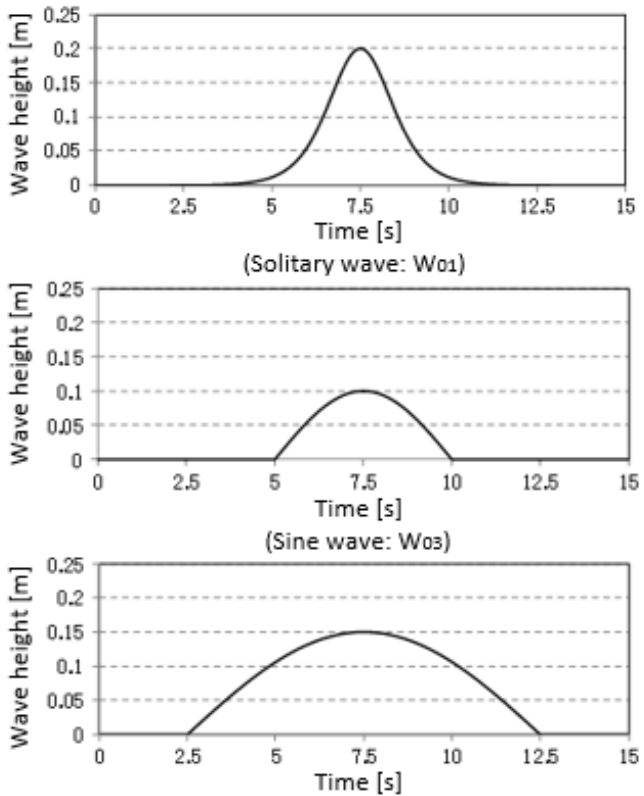

(Sine wave: Wos)

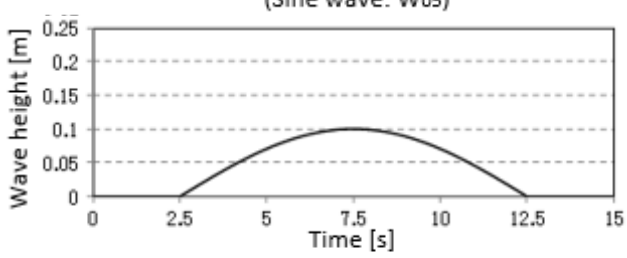

(Sine wave: $\mathrm{W}_{07}$ )


(Long period wave: $W_{11}$ )

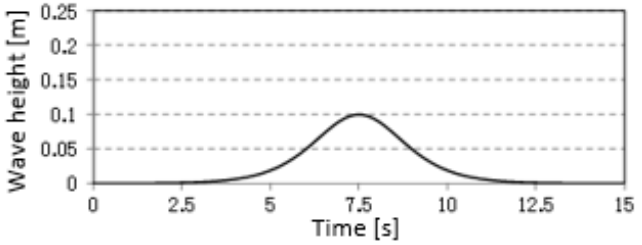

(Solitary wave: W02)

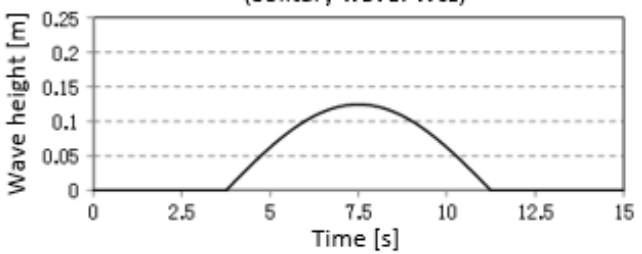

(Sine wave: Wo4)

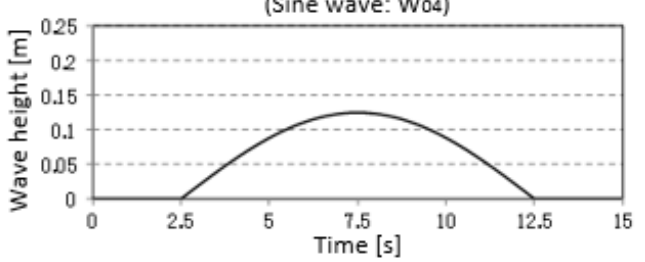

(Sine wave: Wo6)

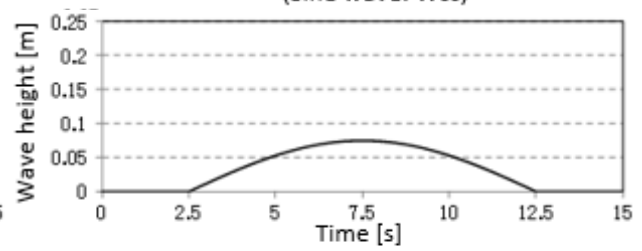

(Sine wave: Wos)
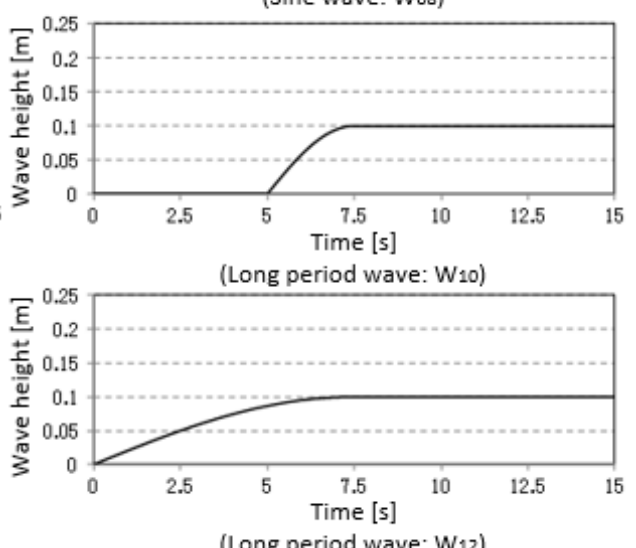

(Long period wave: W12)

Figure 6. Waveforms for flume tests: solitary waves, sine waves, and long period waves.

The test conditions for run-up waves are shown in Table 1 . The offshore-side wave height was measured at $\mathrm{WG}_{1}$ to $\mathrm{WG}_{7}$, and the run-up water depth $(\eta(t))$ was measured at $\mathrm{WG}_{8}$ to $\mathrm{WG}_{10}$.

The test conditions for wave pressure tests are shown in Table 2 . The continuous wave pressures $\left(P_{2 n d}(t)\right)$ acting on the wave pressure gauges were measured, and the continuous wave force $\left(F_{\text {2nd }}(t)\right)$ was calculated by integrating the continuous wave pressures $\left(P_{2 n d}(t)\right)$ in the vertical direction.

The location of wave height gauges and velocity gauges were shown in Fig. 4. These gauges were noise-proof and water-proof. The sampling interval was 0.001 seconds $(1000 \mathrm{~Hz})$. The offshore-side wave height and the run-up water depth $(\eta(t))$ were measured using capacitance type wave height gauges. The offshore-side flow velocity and the flow velocity $(v(t))$ were measured using the electromagnetic velocity gauges, propeller-type velocity gauges and bottom-surface electromagnetic velocity gauges. The continuous wave pressures $\left(P_{2 n d}(t)\right)$ acting on the seawall model were measured using the micro-pressure gauges. 24 wave pressure gauges $\left(\mathrm{PG}_{1}\right.$ to $\left.\mathrm{PG}_{24}\right)$ were set on the surface of the seawall model as shown in Fig. 5. Table 3 shows the measuring range and precision of gauges. Figure. 7 shows the situation of the run-up test and the wave pressure test. 


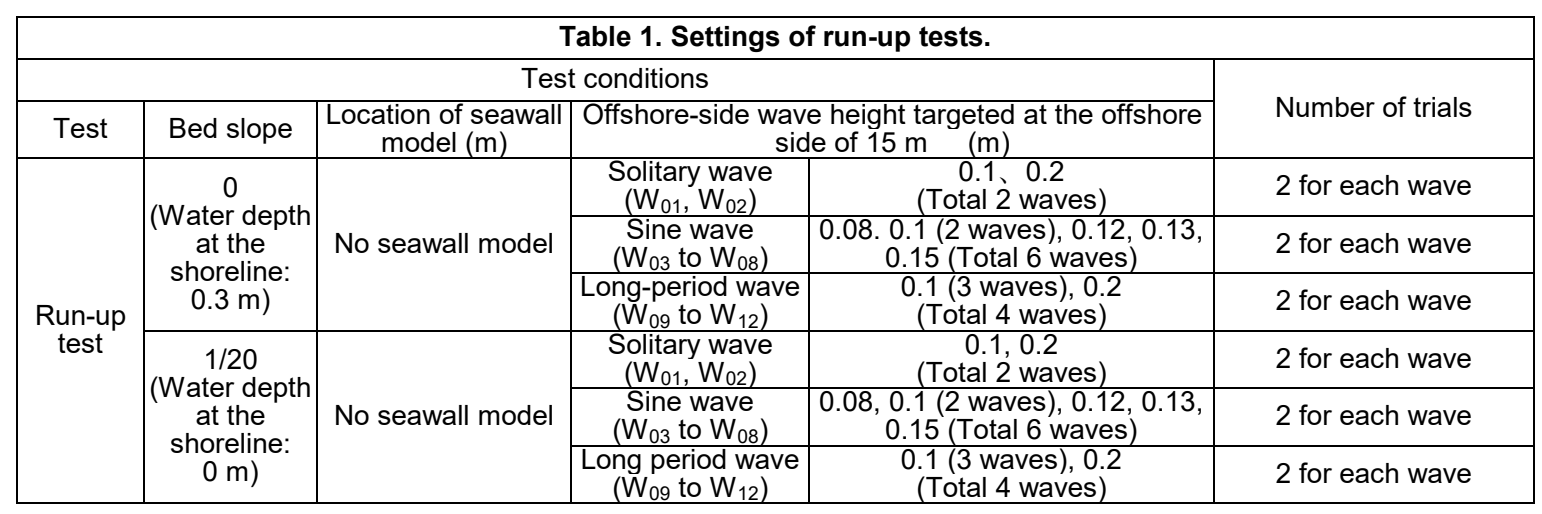

\begin{tabular}{|c|c|c|c|c|c|}
\hline \multicolumn{5}{|c|}{ Test conditions } & \multirow[b]{2}{*}{ Number of trials } \\
\hline Test & Bed slope & \begin{tabular}{|c|} 
Location of seawall \\
model $(\mathrm{m})$
\end{tabular} & $\begin{array}{r}\text { Offshore-side wav } \\
\text { sid }\end{array}$ & $\begin{array}{l}\text { e height targeted at the offshore } \\
\text { le of } 15 \mathrm{~m} \quad(\mathrm{~m})\end{array}$ & \\
\hline \multirow{6}{*}{$\begin{array}{l}\text { Wave } \\
\text { pressure } \\
\text { test }\end{array}$} & \multirow{3}{*}{$\begin{array}{c}0 \\
\text { (Water depth } \\
\text { at the } \\
\text { shoreline: } \\
0.3 \mathrm{~m} \text { ) }\end{array}$} & \multirow{3}{*}{$\begin{array}{c}\text { Shoreline } \\
1.25 \\
2.50\end{array}$} & $\begin{array}{c}\text { Solitary wave } \\
\left(\mathrm{W}_{01}, \mathrm{~W}_{02}\right)\end{array}$ & $\begin{array}{c}0.1,0.2 \\
\text { (Total } 2 \text { waves) } \\
\end{array}$ & $\begin{array}{l}15 \text { for each wave and } \\
\text { each seawall location }\end{array}$ \\
\hline & & & $\begin{array}{c}\text { Sine wave } \\
\left(\mathrm{W}_{03} \text { to } \mathrm{W}_{08}\right)\end{array}$ & $\begin{array}{c}0.08,0.1 \text { (3 waves), } 0.12,0.13 \\
0.15 \\
\text { (Total } 6 \text { waves) }\end{array}$ & $\begin{array}{l}15 \text { for each wave and } \\
\text { each seawall location }\end{array}$ \\
\hline & & & \begin{tabular}{|c|} 
Long period wave \\
$\left(W_{09}\right.$ to $\left.W_{12}\right)$
\end{tabular} & $\begin{array}{c}0.1 \text { ( } 3 \text { waves), } 0.2 \\
\text { (Total } 4 \text { waves) }\end{array}$ & $\begin{array}{l}15 \text { for each wave and } \\
\text { each seawall location }\end{array}$ \\
\hline & \multirow{3}{*}{$\begin{array}{c}1 / 20 \\
\text { (Water depth } \\
\text { at the } \\
\text { shoreline: } \\
0 \mathrm{~m} \text { ) }\end{array}$} & \multirow{3}{*}{$\begin{array}{l}\text { Shoreline1.25 } \\
2.50\end{array}$} & $\begin{array}{c}\text { Solitary wave } \\
\left(\mathrm{W}_{01}, \mathrm{~W}_{02}\right)\end{array}$ & $\begin{array}{c}0.1,0.2 \\
\text { (Total } 2 \text { waves) }\end{array}$ & $\begin{array}{l}15 \text { for each wave and } \\
\text { each seawall location }\end{array}$ \\
\hline & & & \begin{tabular}{|c|} 
Sine wave \\
$\left(\mathrm{W}_{03}\right.$ to $\left.\mathrm{W}_{08}\right)$ \\
\end{tabular} & $\begin{array}{c}0.1 \text { (2 waves), } 0.12,0.13,0.15 \\
\text { (Total } 6 \text { waves) }\end{array}$ & $\begin{array}{l}15 \text { for each wave and } \\
\text { each seawall location }\end{array}$ \\
\hline & & & $\begin{array}{l}\text { Long period wave } \\
\left(W_{09} \text { to } W_{12}\right)\end{array}$ & $\begin{array}{c}0.1 \text { (3 waves), } 0.2 \\
\text { (Total } 4 \text { waves) }\end{array}$ & $\begin{array}{l}15 \text { for each wave and } \\
\text { each seawall location }\end{array}$ \\
\hline
\end{tabular}

\begin{tabular}{|c|c|c|}
\hline \multicolumn{2}{|c|}{ Table 3. Measuring range and precision of gauges. } \\
\hline Gauges Type & Measuring range & Precision \\
\hline Capacitance type wave height gauges & $0 \sim 1800 \mathrm{~mm}$ & $\pm 0.5 \% / \mathrm{FS}$ \\
\hline Electromagnetic velocity gauges & $0 \sim \pm 2000 \mathrm{~mm} / \mathrm{s}$ & $\pm 2 \% / \mathrm{FS}$ \\
\hline Propeller-type velocity gauges & $\pm 30 \sim \pm 4000 \mathrm{~mm} / \mathrm{s}$ & $\pm 30 \mathrm{~mm} / \mathrm{s}$ \\
\hline Bottom-surface electromagnetic velocity gauges & $0 \sim 19.6 \mathrm{kN} / \mathrm{m} 2$ & $\pm 1 \% / \mathrm{FS}$ \\
\hline
\end{tabular}

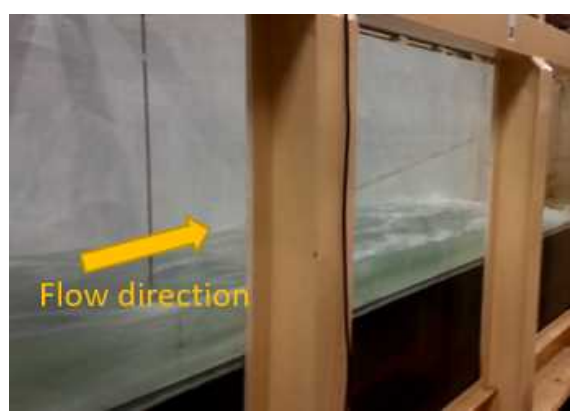

Run-up test

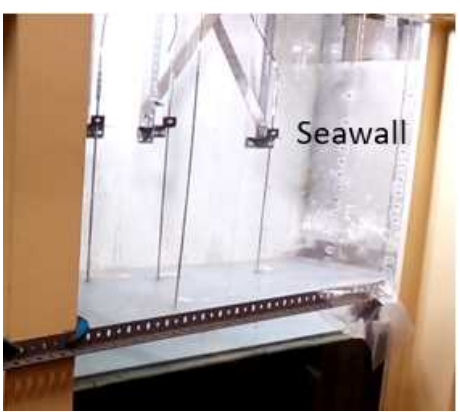

Wave pressure test

Figure 7. Examples of hydraulic flume tests for wave run-up and pressure. 


\section{Test results}

The examples of the run-up water depth $(\eta(t))$, the flow velocity $(v(t))$, the Froude number $(\operatorname{Fr}(t))$, and the specific energy $(E(t))$ of solitary waves and long-period waves at the location of each seawall model are shown in Figs. 8 and 9 respectively. The red dotted lines show the time when the maximum continuous run-up water depth $\left(\eta_{\max 2 n d}\right)$ was measured $\left(t_{\eta \max 2 n d}\right) . t_{\eta \max 2 n d}$ is generally selected as the representative time in MLIT method. The blue dotted lines show the time when the maximum specific energy $\left(E_{\max }\right)$ was measured $\left(t_{E \max }\right)$.

Under the condition that a solitary wave come to the shoreline, the maximum continuous run-up water depth $\left(\eta_{\text {max_2nd }}\right)$ was measured at the time when the leading-edge of the wave reaches the wave height gauges. However, with increasing the distance between the seawall model and the shoreline, the time difference between the leading-edge and $t_{\eta \max \_ \text {2nd }}$ increases, especially in cases of long period waves.

On the other hand, the maximum specific energy $\left(E_{\max }\right)$ was generally measured at the time when the leading-edge of the wave reaches the wave height gauges. At the same time, the Froude number $(F r(t))$ and the flow velocity $(v(t))$ became the maximum as well.
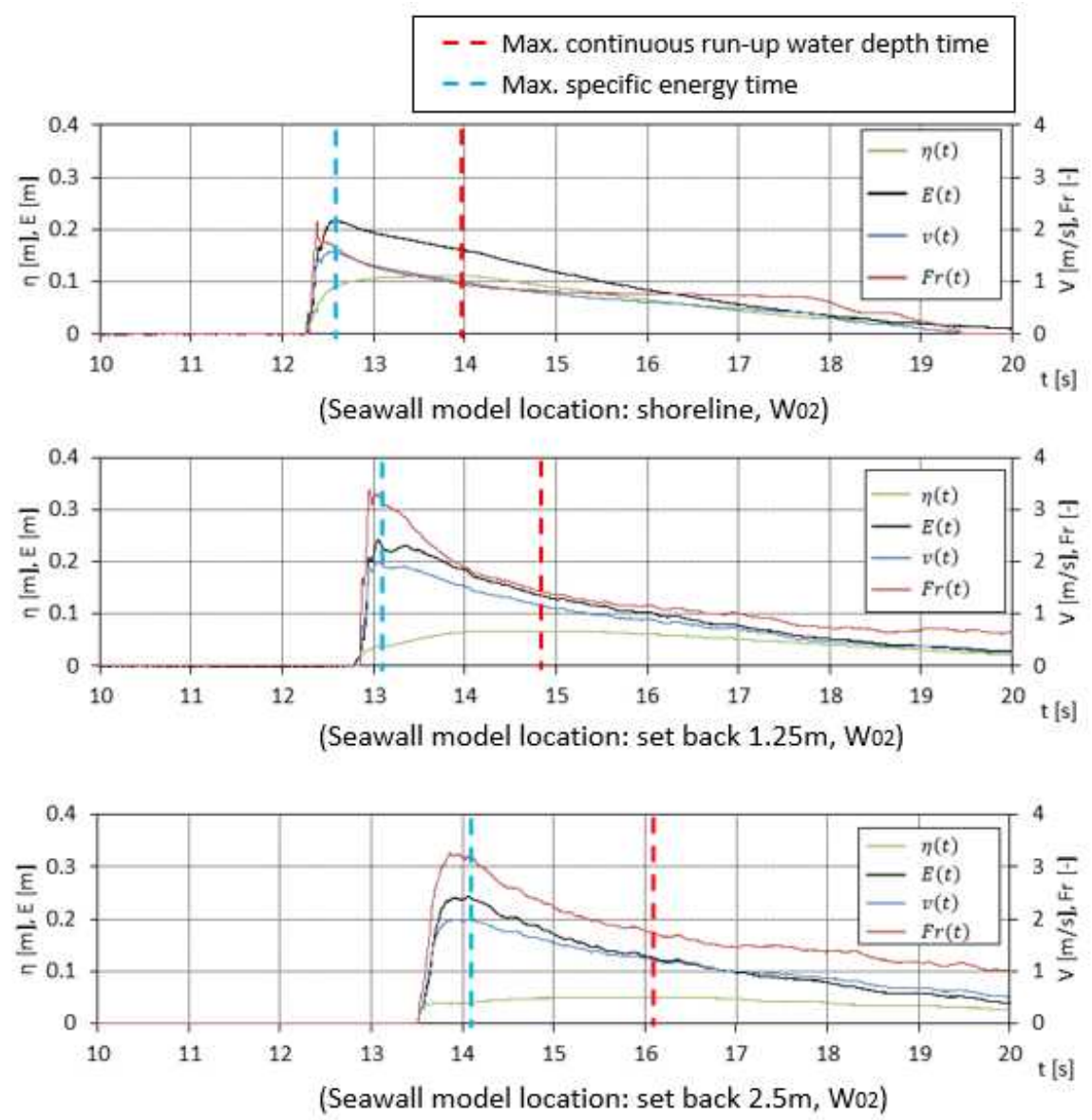

Figure 8. Time histories of run-up water depth, water velocity, specific energy, and Froude number Fr at seawall models (solitary waves $\mathrm{W}_{02}$ for $1 / 20$ slope cases). 

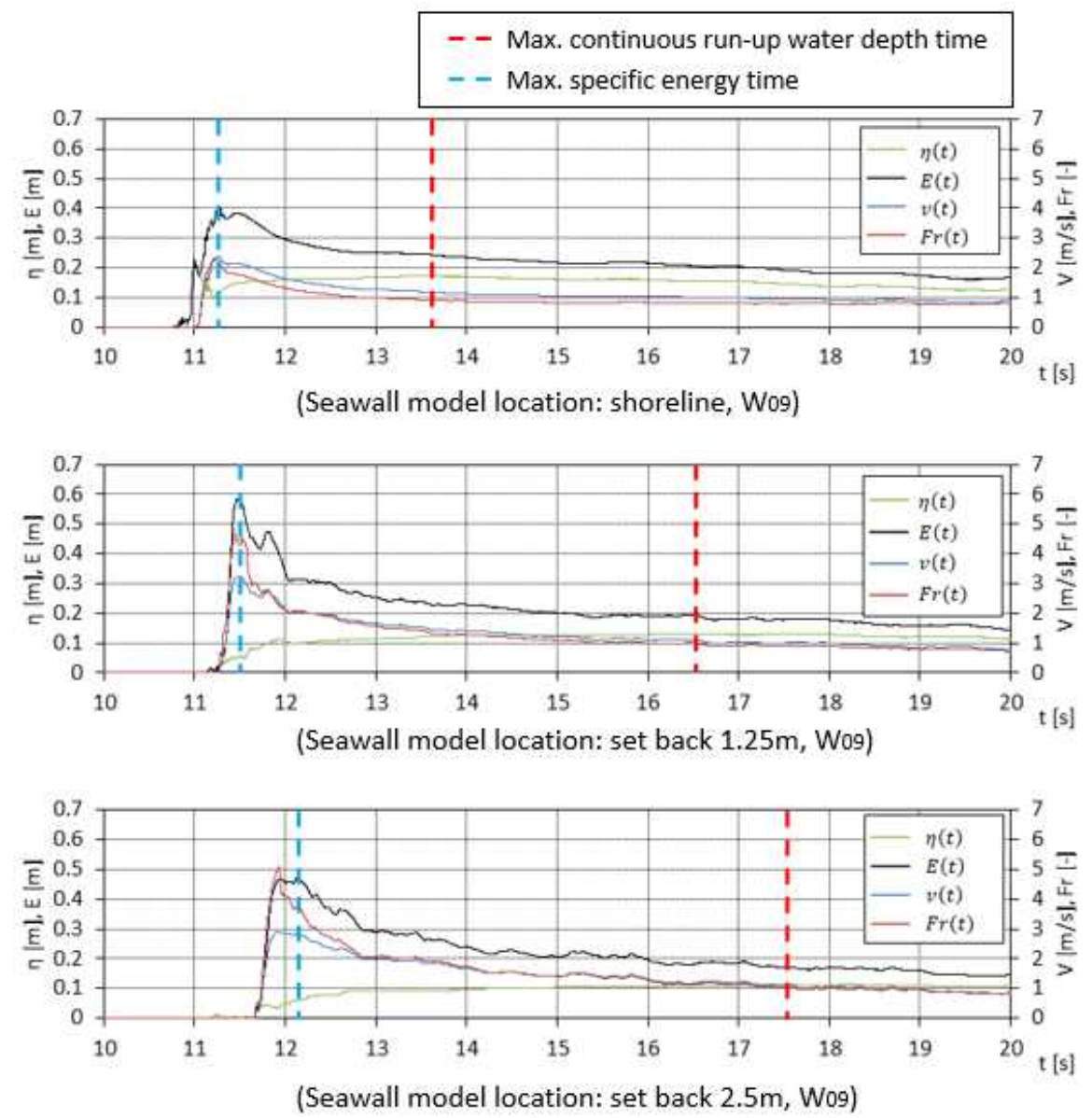

Figure 9. Time histories of run-up water depth, water velocity, specific energy, and Froude number Fr at seawall models (long period waves $W_{09}$ for $1 / 20$ slope cases).

At the wave pressure test, the continuous wave force $\left(F_{2 n d}(t)\right)$ was evaluated by integrating each continuous wave pressure $\left(P_{2 n d}(t)\right)$ in the vertical direction. Figure 10 shows the examples of the continuous wave force $\left(F_{2 n d}(t)\right)$ at the shoreline and at $2.5 \mathrm{~m}$ away from it. The red dotted lines show the time when the maximum continuous wave force $\left(F_{\max \_2 n d}\right)$ were measured $\left(t_{F m a x} 2 n d\right)$. The green dotted lines show $t_{\eta \max \_ \text {2nd }}$ were measured. The black dotted lines show $t_{\text {Emax }}$ were measured. The initial times to generate waves at the run-up test and the wave pressure test were synchronized.

The maximum continuous wave force $\left(F_{\max \_2 n d}\right)$ were measured just after $t_{\text {Emax }}$ rather than $t_{\eta \max \_2 n d}$.

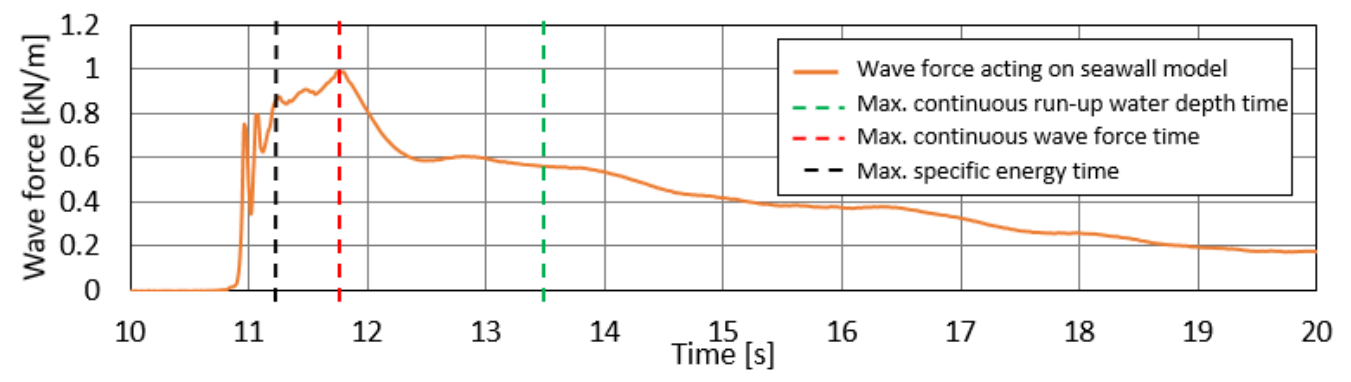




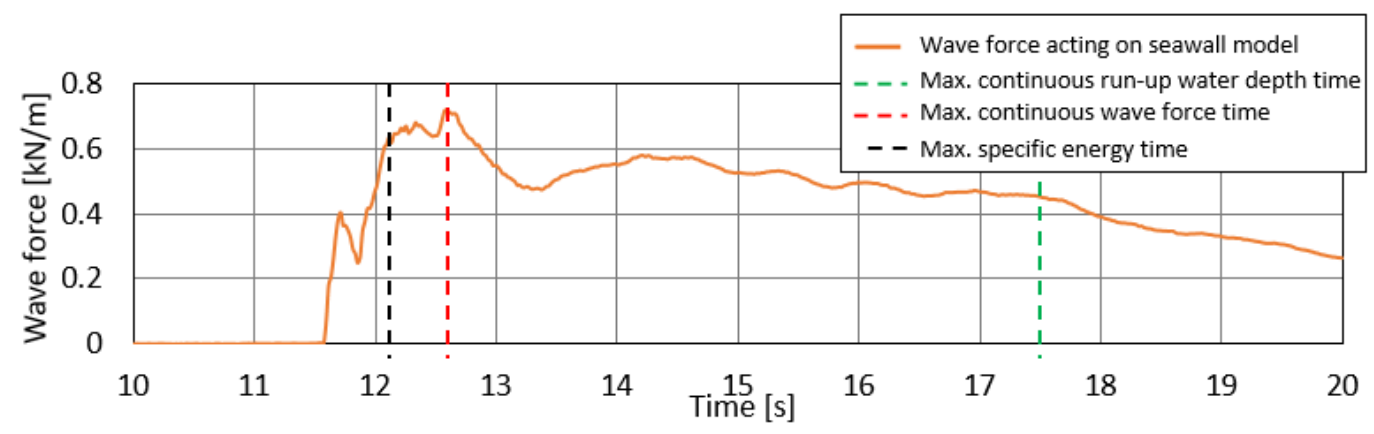

Figure 10. Time history of wave force (long period waves $W_{09}$ for zero slope cases)

(Upper figure: shoreline, lower figure: shoreline -2.5m)

\section{EVALUATIONS FOR TSUNAMI WAVE PRESSURE}

\section{Applicability of MLIT method}

Figure 11 shows our test results for the relationship between the Froude number $\left(F r_{\eta}\right)$ and the water depth coefficient $\left(\alpha_{\eta}\right)$. The linear and the quadratic expression in Fig. 11 are evaluation formulae for the relationship between the Froude number $\left(F r_{\eta}\right)$ and the water depth coefficient $\left(\alpha_{\eta}\right)$, proposed in previous studies.

Our test results were generally consistent with the evaluation formulae. On the other hand, the water depth coefficient $\left(\alpha_{\eta}\right)$ obtained in our test results were higher than the value used in the MLIT method i.e. $\alpha_{\eta}=3$, when the Froude number $\left(F r_{\eta}\right)$ exceeds around 1.That is caused by the strong flow velocity. In the MLIT method, it is assumed that the pressure acting on the seawall model is less than three times the hydrostatic pressure. The pressure includes the hydrodynamic pressure and the hydrostatic pressure. The hydrodynamic pressure and the Froude number $\left(F r_{\eta}\right)$ become high with increasing the flow velocity.

Therefore, it was confirmed that the water depth coefficient $\left(\alpha_{\eta}\right)$ used in the MLIT method i.e. $\alpha_{\eta}=3$, cannot be applied when the Froude number $\left(F r_{\eta}\right)$ is more than 1 .

Moreover, especially when the Froude number $\left(F r_{\eta}\right)$ became large, the data in Fig. 11 was widely scattered even though the Froude numbers $\left(F r_{\eta}\right)$ were almost the same.

This may be related to the flow velocity effect. We used $t_{\eta \max } 2$ 2nd as the representative time and used $\eta_{\max \_2 n d}$ as the design water depth. As shown in Figs. 8 and 9, when the Froude number $\left(F r_{\eta}\right)$ becomes large due to the increase of the distance between the seawall model and the shoreline, $t_{\eta \text { max }}$ 2nd is not consistent with $t_{\text {Fmax_2nd }}$. Using $t_{\eta \max \_ \text {2nd }}$ as the representative time, when the Froude number $\left(F r_{\eta}\right)$ becomes large, it is difficult to estimate the design wave pressure appropriately due to the scattering of the water depth coefficient $\left(\alpha_{\eta}\right)$. 


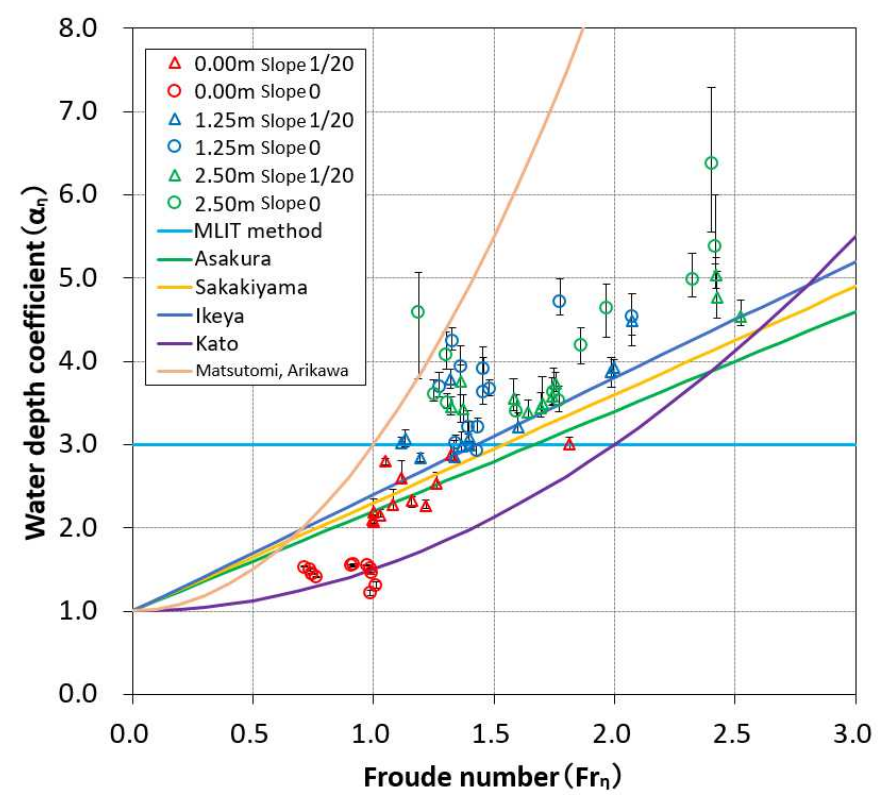

Figure 11. Relationships between Froude number $\left(F r_{\eta}\right)$ and water depth coefficient $\left(\alpha_{\eta}\right)$

(Representative time when run-up water depth become maximum)

\section{Selection of representative time}

To reduce the scattering in the relationship between the Froude number $\left(F r_{\eta}\right)$ and the water depth coefficient $\left(\alpha_{\eta}\right)$ due to the flow velocity effect when the Froude number $\left(F r_{\eta}\right)$ becomes large, more appropriate representative time should be used on the basis of the parameters including the flow velocity effect.

The specific energy $(E(t))$ is the total water energy per unit weight (total hydraulic head), which is the sum of the velocity head induced by the flow velocity $(v(t))$ and the potential head induced by the run-up water depth $(\eta(t))$. Because the specific energy $(E(t))$ is the parameter including the both effects of the run-up water depth $(\eta(t))$ and the flow velocity $(v(t))$, $t_{\text {Emax }}$ was selected as the new representative time, and the run-up water depth $\left(\eta_{E}\right)$ at $t_{E \max }$ was selected as the new design run-up water depth. The representative location was same as the previous one, or the location where the seawall model stands.

The Froude number $\left(F r_{E}\right)$ and the water depth coefficient $\left(\alpha_{E}\right)$ were evaluated on the basis of $t_{E \max }$ as shown in Fig. 12. The Froude number $\left(F r_{E}\right)$ and the water depth coefficient $\left(\alpha_{E}\right)$ were evaluated by using Eqs. (4) and (5). The run-up water depth $\left(\eta_{E}\right)$ is the run-up water depth at $t_{E m a x}$. The flow velocity $\left(\alpha_{E}\right)$ is the flow velocity at $t_{E m a x}$.

$$
\begin{aligned}
F r_{E} & =v_{E} / \sqrt{g \eta_{E}} \\
\alpha_{E} & =\frac{P_{\text {max } \_2 n d}}{\rho g \eta_{E}}
\end{aligned}
$$

Figure 12 which uses the data measured at $t_{E \max }$ shows that the scattering in the relationship between the Froude number $\left(F r_{E}\right)$ and the water depth coefficient $\left(\alpha_{E}\right)$ is less than that of Fig. 11 when the Froude number $\left(F r_{E}\right)$ becomes large.

Therefore, it is reasonable to select the time when the maximum specific energy $\left(E_{\max }\right)$ of the runup wave is measured as the representative time. 


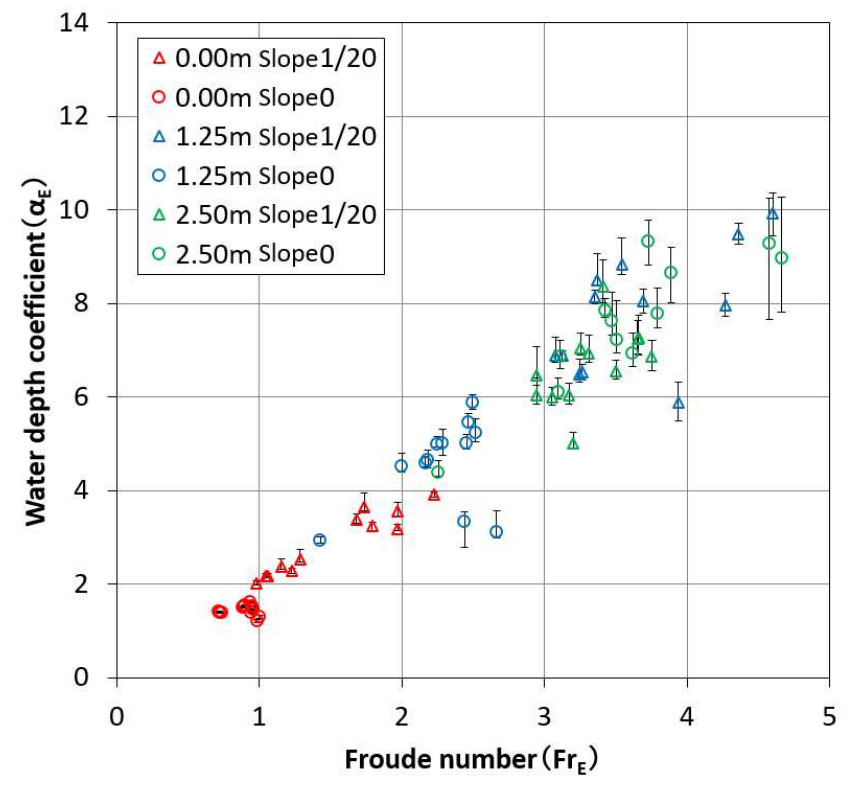

Figure 12. Relationship between Froude number $\left(F r_{E}\right)$ and water depth coefficient $\left(\alpha_{E}\right)$ (Representative time when specific energy becomes maximum).

\section{Theoretical formula}

For including the flow velocity effect, $t_{E \max }$ was selected as the representative time. Since the specific energy $(E(t))$ is based on Bernoulli's theorem, the following theoretical formula Eq. (6) based on the Bernoulli's theorem can be used as the evaluation formula to relate the Froude number $\left(F r_{E}\right)$ and the water depth coefficient $\left(\alpha_{E}\right)$.

$$
\alpha_{\eta}=0.50 F r_{\eta}{ }^{2}+1
$$

Thus, it seems that the regression formula related to the Froude number $\left(F r_{E}\right)$ and the water depth coefficient $\left(\alpha_{E}\right)$ can be assumed as the formula composed of the quadratic term and the constant term 1 $\left(y=a x^{2}+1\right)$ in the same manner as the theoretical formula Eq. (6). The following regression formula Eq. (7) was derived by the least square method from the test results.

$$
\alpha_{E}=0.49 F r_{E}^{2}+1
$$

The test results which were measured $t_{E \max }$ and the formulae of Eq. (6) and Eq. (7) are shown in Fig. 13. The theoretical formula Eq. (6) was consistent with the regression formula Eq. (7). Therefore, it is reasonable to select $t_{E \max }$ as the representative time and to evaluate the maximum continuous wave pressure $\left(P_{\max \_2 n d}\right)$ by using the theoretical formula Eq. (6). 


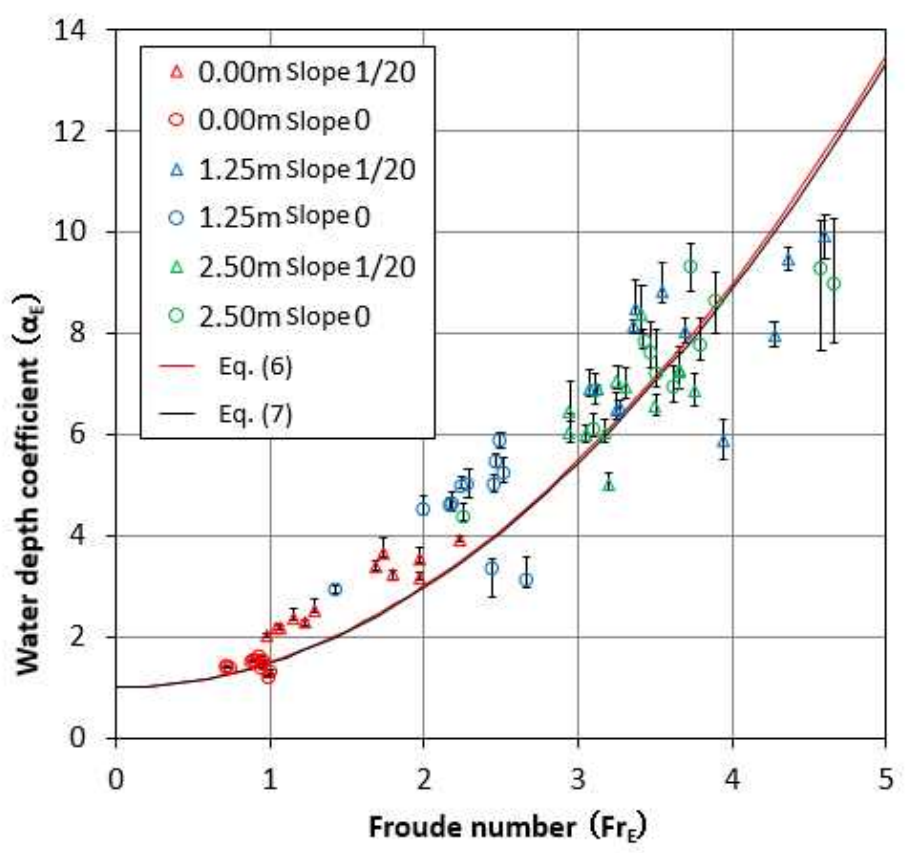

Figure 13. Theoretical regression equations for predicting water depth coefficient $\left(\alpha_{E}\right)$ from Froude number $\left(F r_{E}\right)$.

When the Froude number $\left(F r_{E}\right)$ becomes large, the unsteady and multi-dimensional flow characteristics are significant. Moreover, when the Froude number $\left(F r_{E}\right)$ exceeds 4 , the friction effect to decrease the wave pressure as increasing the flow velocity should be considered. On the other hand, the theoretical formula Eq. (6) was assumed as the one-dimensional steady state flow on the basis of the Bernoulli's theorem, and the friction effect was assumed to be zero.

As shown in Fig. 13, the test results and the theoretical formula Eq. (6) were relatively consistent between Froude numbers $\left(F r_{E}\right) 1$ and 4, however, when the Froude number $\left(F r_{E}\right)$ became more than 4, the theoretical formula Eq. (6) exceeded test results. That is caused by the unsteady and multidimensional flow characteristics as well as the friction effect from the flow velocity to the wave pressure. Hence, the applicable range should be considered to the theoretical formula Eq. (6). From test results, the theoretical formula Eq. (6) can be applied when the Froude number $\left(F r_{E}\right)$ becomes less than around 4.

Therefore, Eq. (6) 6 has the upper limitation of Froude number $\left(F r_{E}\right)$ of 4 , which can be rewritten as follows:

$$
\alpha_{E}=0.50 F r_{E}^{2}+1 \quad\left(F r_{E} \leq 4\right)
$$

\section{Design method for a seawall}

As we mentioned, the MLIT method to evaluate the design wave pressure acting on the seawall can be applied until the Froude number $\left(F r_{\eta}\right)$ reaches 1 . The design wave pressure evaluation formula based on Eq. (8) was developed as the applicable method to evaluate the design wave pressure beyond the Froude number $\left(F r_{\eta}\right)$ of 1 .

Assuming that the test results distributed as a lognormal distribution because the water depth coefficient is a positive value, the logarithmic standard deviation (sigma $=0.21$ ) was obtained from the test results and Eq. (8). The lognormal distribution is applied to the distribution of a natural phenomenon witch takes only positive values.

For enveloping all test results, three standard deviations from the mean were selected temporarily as the logarithmic standard deviation included in the design wave pressure evaluation formula Eq. (9).

$$
\alpha_{E}=1.90 \times\left(0.50 F r_{E}^{2}+1\right) \quad\left(F r_{E} \leq 4\right)
$$


The test results which were measured at $t_{E \max }$ and Eq. (9) were shown in Fig. 14. As shown in Fig. 14, the intersection of Eq. (9) and the horizontal line of water depth coefficient $\left(\alpha_{E}\right) 3$ exists around the Froude number $\left(F r_{E}\right)$ of 1.1. Note that the Froude number $\left(F r_{\eta}\right)$ used by the MLIT method was based on the test results measured at $t_{\eta \max \_2 n d}$, while the Froude number $\left(F r_{E}\right)$ used by Eq. (9) was based on the test results measured at $t_{E m a x}$. Although the Froude number $\left(F r_{\eta}\right)$ and the Froude number $\left(F r_{E}\right)$ were different values, both were almost the same value under the condition of the small Froude number $\left(F r_{E}\right)$ due to the small flow velocity. Since the Froude number $\left(F r_{E}\right)$ were equivalent to the Froude number $\left(F r_{\eta}\right)$ at the small Froude number $\left(F r_{E}\right)$, the MLIT method can be used until the Froude number $\left(F r_{E}\right)$ less than 1.1.

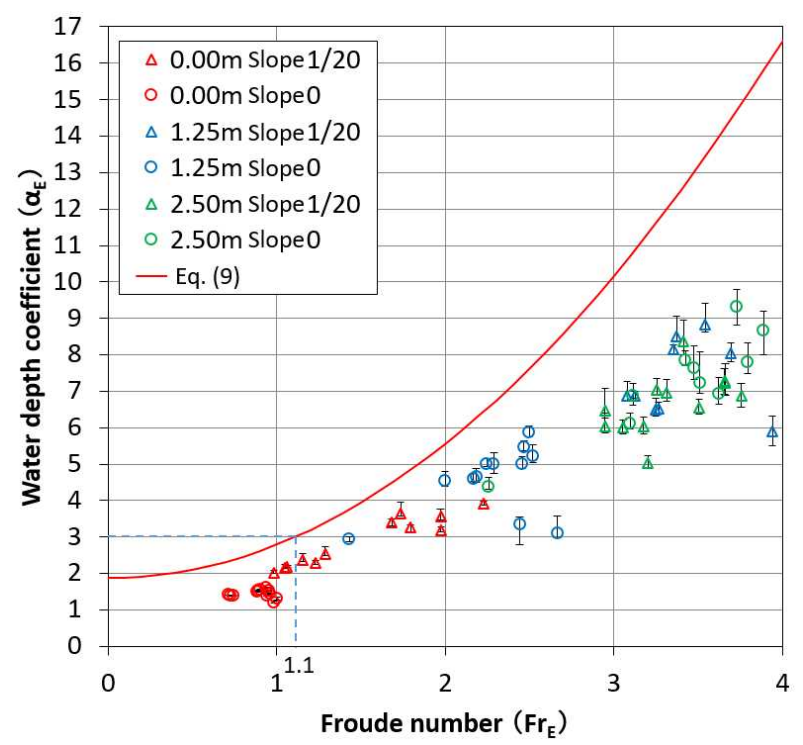

Figure 14. Design evaluation examples for water depth coefficient $\left(\alpha_{E}\right)$ with three standard deviations, assuming a lognormal distribution.

The MLIT method is simple and has been commonly used in Japan to evaluate the design wave pressure acting on the seawall. In addition, it can be used until the Froude number $\left(F r_{E}\right)$ less than 1.1. Therefore, as one of the design wave pressure evaluation methods for design wave pressure acting on the seawall, we developed the design wave pressure evaluation method which has two region of the Froude number $\left(F r_{E}\right)$ as follows.

- The water depth coefficient $\left(\alpha_{E}\right) 3$ is applicable for the Froude number $\left(F r_{E}\right)$ less than 1.1.

- The design wave pressure evaluation formula Eq. (9) is applicable in the region where the Froude number $\left(F r_{E}\right)$ is more than 1.1 and less than 4.

\section{CONCLUSIONS}

This paper confirmed the applicable condition of the MLIT method which was used as the design wave pressure evaluation method acting on the seawall. We conducted some hydraulic flume tests and developed a new design evaluation method that can be applied for the case including the Froude number $\left(F r_{\eta}\right)$ higher than 1 .

As the results, until Froude number $\left(F r_{\eta}\right)$ reaches 1, the water depth coefficient $\left(\alpha_{\eta}\right)$ used in the MLIT method i.e. $\alpha_{\eta}=3$, can be applied. On the other hand, beyond the Froude number $\left(F r_{\eta}\right)$ of 1 , the water depth coefficient $\left(\alpha_{\eta}\right)$ exceeds 3 and the MLIT method cannot be applied. As the design water pressure evaluation method when the Froude number $\left(F r_{\eta}\right)$ is more than 1, the following method based on the Froude number $\left(F r_{E}\right)$ and water depth coefficient $\left(\alpha_{E}\right)$ were developed. As for the representative time for that method, $t_{\text {Emax }}$ was selected.

- $\quad$ The water depth coefficient $\left(\alpha_{E}\right) 3$ is applicable for the Froude number $\left(F r_{E}\right)$ less than 1.1.

- The design wave pressure evaluation formula Eq. (9) is applicable in the region where the Froude number $\left(F r_{E}\right)$ is more than 1.1 and less than 4. 


\section{ACKNOWLEDGMENTS}

The support of the "TAISEI CORPORATION" for the hydraulic flume test is gratefully acknowledged.

\section{REFERENCES}

Effects of Bore Pressure of Tsunami on Seawall, NTEC-2015-4001, Regulatory Standard and Research Department Secretariat of Nuclear Regulation Authority (S/NRA/R), 2015

Water Depth Coefficients for Evaluating Tsunami Pressure on Seawall, NTEC-2016-4001, Regulatory Standard and Research Department Secretariat of Nuclear Regulation Authority (S/NRA/R), 2016

The interim guidelines of the Ministry of Land, Infrastructure, Transport and Tourism, 2011

Asakura R. 2002. The tsunami wave force acting on land structures, Coastal Engineering, ASCE, pp.1191-1202

Sakakiyama T. 2012. Tsunami Inundation Flow and Tsunami Pressure on Structures, Journal of JSCE B2 (Coastal Engineering), Vol68 No2, pp.I_771-I_775

Ikeya T. 2013. On the Hydraulic Mechanism of Sustained Tsunami Wave Pressure Acting on Land Structures, Journal of JSCE B2 (Coastal Engineering), Vol69 No2, pp.I_816-I_820

Kato F. 2012. A Method to Estimate Tsunami Setup in Front of Buildings, Journal of JSCE B2 (Coastal Engineering), Vol68 No2, pp.I_331-I_335

Matsutomi H. 2013. Experiments on Tsunami Fluid Force Acting on a Reinforced Concrete Building with Aperture, Journal of JSCE B2 (Coastal Engineering), Vol69 No2, pp.I_326-I_330

Arikawa T. 2015. Consideration of Characteristics of Pressure on Seawall by Solitary Waves Based on Hydraulic Experiments, Journal of JSCE B2 (Coastal Engineering), Vol71 No2, pp.I_889-I_894 